\title{
Synthesis and cytotoxicity evaluation of thiazole derivatives obtained from 2-amino-4,5,6,7-tetrahydrobenzo[b]thiophene- 3-carbonitrile
}

\author{
RAFAT M. MOHAREB ${ }^{1}$ \\ AMIRA E. M. ABDALLAH ${ }^{2 *}$ \\ EBTSAM A. AHMED ${ }^{2}$ \\ ${ }^{1}$ Department of Chemistry \\ Faculty of Science \\ Cairo University, Giza, A. R. Egypt \\ ${ }^{2}$ Department of Chemistry \\ Faculty of Science, Helwan University \\ Ain Helwan, Cairo A. R. Egypt
}

\begin{abstract}
Reactivity of 2-amino-4,5,6,7-tetrahydrobenzo[b]thiophene3-carbonitrile towards thioglycolic acid resulted in thiazole derivative 1 . The latter reacted with different chemical reagents to give thiazole, pyrano[2,3- $d]$ thiazole and thiazolo[4,5-d]thiazole derivatives. Cytotoxicity effects of the newly synthesized products against six cancer cell lines, namely, human gastric cancer (NUGC), human colon cancer (DLD1), human liver cancer (HA22T and HEPG-2), human breast cancer (MCF) and nasopharyngeal carcinoma (HONE-1) as well as against a normal fibroblast cell (WI-38) were evaluated. The study showed that the $4,5,6,7$ tetrahydrobenzo[ $b]$ thiophene derivatives $6 a, 7,8 a, b, 9 b$ and $10 b, c$ were the most active compounds. Their potencies were attributed to the presence of the electron withdrawing groups.
\end{abstract}

Keywords: tetrahydrobenzo[b]thiophene, thiazole, pyrano[2,3-d] thiazole, thiazolo[4,5-d]thiazole, cytotoxicity, anticancer activity

A number of thiazole derivatives were synthesized according to the Hantzsch thiazole synthesis (1), along with other methods (2-7). Heterocyclic compounds containing thiazole moiety were found to exhibit a wide spectrum of biological activities such as antioxidant (8), antitubercular $(9,10)$, diuretic (11), antischizophrenia (12), antibacterial (13, 14), anti-inflammatory (15), anti-HIV (16), antihypertensive (17), antiallergic (18), hypnotic (19), analgesic (20), antitumor and cytotoxic $(21,22)$. Thiazole moiety is present in many drugs such as thiamine (vitamin $\mathrm{B}_{1}$ ), penicillin (antibiotic), sulfathiazole (antibacterial drug), 2-(4-chlorophenyl)thiazole-4-ylacetic (anti-inflammatory agent), thiabendazole [2-(4-thiazolyl)benzimidazole] (anthelmintic and fungicide), and niridazole [1-(5-nitro-2thiazolyl)-2-imidazolidinone] (schistosomicidal agent) $(23,24)$. Some thiazole derivatives have been recently proven to be anticancer agents (25). In the present study, we demonstrated the reaction of 4,5,6,7-tetrahydrobenzo[b]thiophene with thioglycolic acid to produce new thiazole derivatives incorporating thiophene moiety and studied their cytotoxicity against different cancer cell lines.

\footnotetext{
*Correspondence; e-mail: amiraelsayed135@yahoo.com; miroemao@yahoo.com
} 


\section{EXPERIMENTAL}

\section{General}

All melting points were uncorrected and determined on an electrothermal apparatus (Büchi 535, Switzerland) in an open capillary tube. IR spectra ( $\mathrm{KBr}$ discs) were recorded on a FTIR plus 460 IR spectrophotometer (Shimadzu, Japan). ${ }^{13} \mathrm{C}$ NMR and ${ }^{1} \mathrm{H}$ NMR spectra were recorded on a Varian Gemini-200 (200 MHz) (USA) spectrometer in DMSO- $d_{6}$ as solvent, using TMS as internal reference and chemical shifts $(\delta, \mathrm{ppm})$. Mass spectra were recorded using a Hewlett Packard 5988 (USA) GC/MS system and GCMS-QP 1000 Ex Shimadzu (Japan) using EI (electron impact method). Elemental analyses were carried out on a Vario EL III Elemental CHNS analyzer (Elementar Analysensysteme GmbH, Germany).

\section{Syntheses}

2-(2-Amino-4,5,6,7-tetrahydrobenzo[b]thiophen-3-yl)thiazol-4(5H)-one (1). - To a solution of 2-amino-4,5,6,7-tetrahydrobenzo[b]thiophene-3-carbonitrile $(1.78 \mathrm{~g}, 0.01 \mathrm{~mol})$ in acetic acid $(30 \mathrm{~mL})$, thioglycolic acid $(0.92 \mathrm{~g}, 0.01 \mathrm{~mol})$ was added. The reaction mixture was heated under reflux for $3 \mathrm{~h}$, then poured into ice/water and the formed solid product was collected by filtration and crystallized from ethanol.

2-Cyano-N-(4,5,6,7-tetrahydro-3-(4,5-dihydro-4-oxothiazol-2-yl)benzo[b]thiophen-2-yl)acetamide (2). - To compound $\mathbf{1}$ (2.52 g, $0.01 \mathrm{~mol})$ in dimethylformamide $(30 \mathrm{~mL})$, ethyl cyanoacetate $(1.13 \mathrm{~g}, 0.01 \mathrm{~mol})$ was added, then heated in a reflux system for $4 \mathrm{~h}$ and poured into an ice/water mixture. The formed solid product was collected by filtration and crystallized from dimethylformamide.

1-(4,5,6,7-Tetrahydro-3-(4,5-dihydro-4-oxothiazol-2-yl)benzo[b]thiophen-2-yl)-3-phenylthiourea (3). - To the dry solid of compound 1 ( $2.52 \mathrm{~g}, 0.01 \mathrm{~mol})$ in 1,4-dioxane ( $35 \mathrm{~mL})$ containing a catalytic amount of triethylamine $(0.50 \mathrm{~mL})$, phenylisothiocyanate $(1.35 \mathrm{~g}, 0.01$ mol) was added. The whole reaction mixture was heated under reflux for $4 \mathrm{~h}$, then poured into an acidified ice/water mixture. The formed solid product was collected by filtration and crystallized from 1,4-dioxane.

1-(3-(5-(2-Phenylhydrazono)-4,5-dihydro-4-oxothiazol-2-yl)-4,5,6,7-tetrahydrobenzo[b] thiophen-2-yl)-3-phenylthiourea (4). - To a cold solution $\left(0-5{ }^{\circ} \mathrm{C}\right)$ of compound $3(3.87 \mathrm{~g}, 0.01$ $\mathrm{mol})$ in ethanol $(50 \mathrm{~mL})$ containing sodium hydroxide $(0.40 \mathrm{~g}, 0.01 \mathrm{~mol})$, benzenediazonium chloride $(0.01 \mathrm{~mol})$ [prepared by adding a cold solution of sodium nitrite $(0.69 \mathrm{~g}, 0.01 \mathrm{~mol})$ in water $(10 \mathrm{~mL})$ to a cold solution $\left(0-5{ }^{\circ} \mathrm{C}\right)$ of aniline $(0.93 \mathrm{~g}, 0.01 \mathrm{~mol})$ in concentrated hydrochloric acid $(12 \mathrm{~mL})$ under continuous stirring] was added under continuous stirring. The whole reaction mixture was left at room temperature for $1 \mathrm{~h}$ and the solid product formed was collected by filtration and crystallized from ethanol.

2-(2-Amino-4,5,6,7-tetrahydrobenzo[b]thiophen-3-yl)-5-bromo-thiazol-4(5H)-one (5) - To a solution of compound $1(2.52 \mathrm{~g}, 0.01 \mathrm{~mol})$ in acetic acid $(40 \mathrm{~mL})$ at $50{ }^{\circ} \mathrm{C}$, bromine $(1.80 \mathrm{~g}$, $0.01 \mathrm{~mol}$ ) was added dropwise. The reaction mixture was kept at room temperature for 1 $\mathrm{h}$ under continuous stirring. The solid product, when poured into an ice/water mixture, was collected by filtration and recrystallized from acetic acid. 
R. M. Mohareb et al.: Synthesis and cytotoxicity evaluation of thiazole derivatives obtained from 2-amino-4,5,6,7-tetrahydrobenzo[b] thiophene-3-carbonitrile, Acta Pharm. 67 (2017) 495-510.

2-(2-Amino-4,5,6,7-tetrahydrobenzo[b]thiophen-3-yl)-7-imino-7H-pyrano[2,3-d] thiazol-5amine $(6 a)$ and 2-(2-amino-4,5,6,7-tetrahydrobenzo[b]thiophen-3-yl)-7-imino-7H-pyrano[2,3-d] thiazol-5-ol (6b). General procedure. - To a solution of compound $\mathbf{1}(2.52 \mathrm{~g}, 0.01 \mathrm{~mol})$ in 1,4-dioxane $(40 \mathrm{~mL})$ containing triethylamine $(0.50 \mathrm{~mL})$, either malononitrile $(0.66 \mathrm{~g}, 0.01 \mathrm{~mol})$ or ethyl cyanoacetate $(1.13 \mathrm{~g}, 0.01 \mathrm{~mol})$ was added. The reaction mixture, in each case, was heated under reflux for $5 \mathrm{~h}$, left to cool and then poured into an ice/water mixture containing a few drops of hydrochloric acid. The formed solid product, in each case, was collected by filtration and re-crystallized from 1,4-dioxane.

5-(2-Amino-4,5,6,7-tetrahydrobenzo[b]thiophen-3-yl)-3-phenyl-thiazolo[4,5-d]thiazole2(3H)-thione (7). - To a mixture of compound 1 (2.52 g, $0.01 \mathrm{~mol})$ in 1,4-dioxane (35 mL) containing triethylamine $(0.50 \mathrm{~mL})$, elemental sulfur $(0.32 \mathrm{~g}, 0.01 \mathrm{~mol})$ and phenylisothiocyanate $(1.35 \mathrm{~g}, 0.01 \mathrm{~mol})$ were added. The reaction mixture was heated under reflux for 5 $\mathrm{h}$ and then poured into a beaker containing an acidified ice/water mixture. The solid product was collected by filtration, dried and then recrystallized from 1,4-dioxane.

5-(2-Phenylhydrazono)-2-(2-amino-4,5,6,7-tetrahydrobenzo[b]thiophen-3-yl)thiazol-4(5H)-one (8a), (5E)-5-(2-(4-chlorophenyl)hydrazono)-2-(2-amino-4,5,6,7-tetrahydrobenzo[b]thiophen-3-yl) thiazol-4(5H)-one (8b), 5-(2-(4-methoxyphenyl)-hydrazono)-2-(2-amino-4,5,6,7-tetrahydrobenzo[b]thiophen-3-yl)thiazol-4(5H)-one (8c) and 5-(2-p-tolylhydrazono)-2-(2-amino-4,5,6,7-tetrahydrobenzo[b]thiophen-3-yl)thiazol-4(5H)-one (8d). General procedure. - To a cold solution $(0-5$ $\left.{ }^{\circ} \mathrm{C}\right)$ of compound $1(2.52 \mathrm{~g}, 0.01 \mathrm{~mol})$ in ethanol $(50 \mathrm{~mL})$ containing sodium hydroxide $(10 \%$, $10 \mathrm{~mL})$, a solution of either benzenediazonium chloride $(0.01 \mathrm{~mol})$ or $p$-chlorobenzenediazonium chloride $(0.01 \mathrm{~mol})$ or $p$-methoxybenzenediazonium chloride $(0.01 \mathrm{~mol})$ or $p$-methylbenzenediazonium chloride $(0.01 \mathrm{~mol})$ [prepared by dissolving sodium nitrite $(0.70 \mathrm{~g}, 0.01$ $\mathrm{mol})$ in water $(2 \mathrm{~mL})$ and added to a cold solution of aniline $(0.93 \mathrm{~g}, 0.01 \mathrm{~mol}), p$-chloroaniline (1.27 g, $0.01 \mathrm{~mol}), p$-methoxyaniline $(1.23 \mathrm{~g}, 0.01 \mathrm{~mol})$ or $p$-toluidine $(1.07 \mathrm{~g}, 0.01 \mathrm{~mol})$, containing an appropriate amount of hydrochloric acid under continuous stirring] was added under continuous stirring. The solid product formed, in each case, was collected by filtration and dried, and then recrystallized from ethanol.

Ethyl-2-cyano-2-(2-(3-(4-oxo-4,5-dihydrothiazol-2-yl)-4,5,6,7-tetrahydrobenzo[b]thiophen2-yl)hydrazono)acetate (9a), (3-(4-oxo-4,5-dihydrothiazol-2-yl)-4,5,6,7-tetrahydrobenzo[b]thiophen-2-yl)carbonohydrazonoyl dicyanide (9b), dimethyl-2-(2-(3-(4-oxo-4,5-dihydrothiazol-2-yl)4,5,6,7-tetrahydrobenzo[b]thiophen-2-yl)hydrazono)malonate (9c) and diethyl-2-(2-(3-(4-oxo-4,5dihydrothiazol-2-yl)-4,5,6,7-tetrahydrobenzo[b]thiophen-2-yl)-hydrazono)malonate (9d). General procedure - To a cold solution $\left(0-5{ }^{\circ} \mathrm{C}\right)$ of the diazotized compound $\mathbf{1}$ [prepared by adding a $\mathrm{NaNO}_{2}(0.69 \mathrm{~g}, 0.01 \mathrm{~mol})$ solution to a cold solution of $1(2.52 \mathrm{~g}, 0.01 \mathrm{~mol})$ in acetic acid $(20 \mathrm{~mL})$ and $\mathrm{HCl}(6 \mathrm{~mL}, 18 \%)]$, either ethyl cyanoacetate $(1.13 \mathrm{~g}, 0.01 \mathrm{~mol})$ or malononitrile $(0.66 \mathrm{~g}$, $0.01 \mathrm{~mol})$ or acetyl acetone $(1.00 \mathrm{~g}, 0.01 \mathrm{~mol})$ or malonic acid diethyl ester $(1.60 \mathrm{~g}, 0.01 \mathrm{~mol})$ in ethanol $(20 \mathrm{~mL})$ containing sodium hydroxide $(1.00 \mathrm{~g})$ was gradually added under stirring. Upon cooling in an ice-bath, a solid product formed in each case. It was collected by filtration, washed with water and crystallized from ethanol.

2-(2-Amino-4,5,6,7-tetrahydrobenzo[b]thiophen-3-yl)-5-benzylidenethiazol-4(5H)-one (10a), 5-(4-chlorobenzylidene)-2-(2-amino-4,5,6,7-tetrahydrobenzo[b]thiophen-3-yl)thiazol4(5H)-one (10b), 5-(4-methoxybenzylidene)-2-(2-amino-4,5,6,7-tetrahydrobenzo[b]thiophen-3-yl) 
thiazol-4(5H)-one (10c) and 5-(2-hydroxybenzylidene)-2-(2-amino-4,5,6,7-tetrahydrobenzo[b] thiophen-3-yl)thiazol-4(5H)-one (10d). General procedure. - To a solution of compound $\mathbf{1}(2.52 \mathrm{~g}$, $0.01 \mathrm{~mol})$ in 1,4-dioxane and a catalytic amount of piperidine $(0.50 \mathrm{~mL})$, either benzaldehyde $(1.06 \mathrm{~g}, 0.01 \mathrm{~mol})$ or $p$-chlorobenzaldehyde $(1.12 \mathrm{~g}, 0.01 \mathrm{~mol})$ or $p$-methoxy-benzaldehyde $(1.08 \mathrm{~g}, 0.01 \mathrm{~mol})$ or salicylaldehyde $(1.22 \mathrm{~g}, 0.01 \mathrm{~mol})$ were added. The reaction mixture was heated under reflux for $5 \mathrm{~h}$, then poured into an acidified ice/water mixture. The formed solid product, in each case, was collected by filtration and recrystallized from 1,4-dioxane.

\section{In vitro cytotoxic assay}

Fetal bovine serum (FBS) and $L$-glutamine were purchased from the Gibco Invitrogen Company (UK). RPMI-1640 medium was purchased from Cambrex (USA). Dimethyl sulfoxide (DMSO), CHS-828, penicillin, streptomycin and sulforhodamine B (SRB) were purchased from the Sigma Chemical Company (USA).

No experiments were done on humans. Cancer and normal human cell lines were purchased. Cell cultures were obtained from the European Collection of Cell Cultures (ECACC, Salisbury, UK) while human gastric cancer (NUGC and HR), human colon cancer (DLD-1), human liver cancer (HA22T and HEPG-2), human breast cancer (MCF-7), nasopharyngeal carcinoma (HONE-1) and normal fibroblast cells (WI-38) were kindly provided by the National Cancer Institute (NCI, Cairo, Egypt). Cell lines grew as monolayers and were routinely maintained in RPMI-1640 medium supplemented with $5 \%$ heat inactivated FBS, $2 \mathrm{mmol} \mathrm{L}^{-1}$ glutamine and antibiotics (penicillin $100 \mathrm{U} \mathrm{mL}^{-1}$, streptomycin $100 \mu \mathrm{g}$ $\mathrm{mL}^{-1}$ ), at $37{ }^{\circ} \mathrm{C}$ in a humidified atmosphere containing $5 \% \mathrm{CO}_{2}$. Exponentially growing cells were obtained by plating $1.5 \times 10^{5}$ cells $\mathrm{mL}^{-1}$ for the six human cancer cell lines, followed by $24 \mathrm{~h}$ of incubation.

The prepared heterocyclic compounds were evaluated according to standard protocols for their in vitro cytotoxicity (26-28) against the six human cancer cell lines: human gastric cancer (NUGC), human colon cancer (DLD-1), human liver cancer (HA22T and HEPG-2), human breast cancer (MCF-7) and nasopharyngeal carcinoma (HONE-1), as well as normal fibroblast cells (WI-38).

The reference compound was (Z)-(6-(4-chlorophenoxy)hexyl)-3-cyano-2-(pyridin-4yl)guanidine (CHS-828), which is an antitumor agent. The effect of vehicle solvent (DMSO) on the growth of these cell lines was evaluated in all experiments by exposing untreated control cells to the maximum concentration $(0.5 \%)$ of DMSO used in each assay.

\section{RESULTS AND DISCUSSION}

\section{Chemistry}

The reaction of 2-amino-4,5,6,7-tetrahydrobenzo[b]thiophene-3-carbonitrile with thioglycolic acid gave the thiazole derivative 1 . The structure of compound 1 was confirmed on the basis of analytical and spectral data. Thus, the ${ }^{1} \mathrm{H}$ NMR spectrum showed the presence of multiplets at $\delta 1.69-1.75$ and $\delta 2.50-2.57 \mathrm{ppm}$ for the four $\mathrm{CH}_{2}$ groups of 


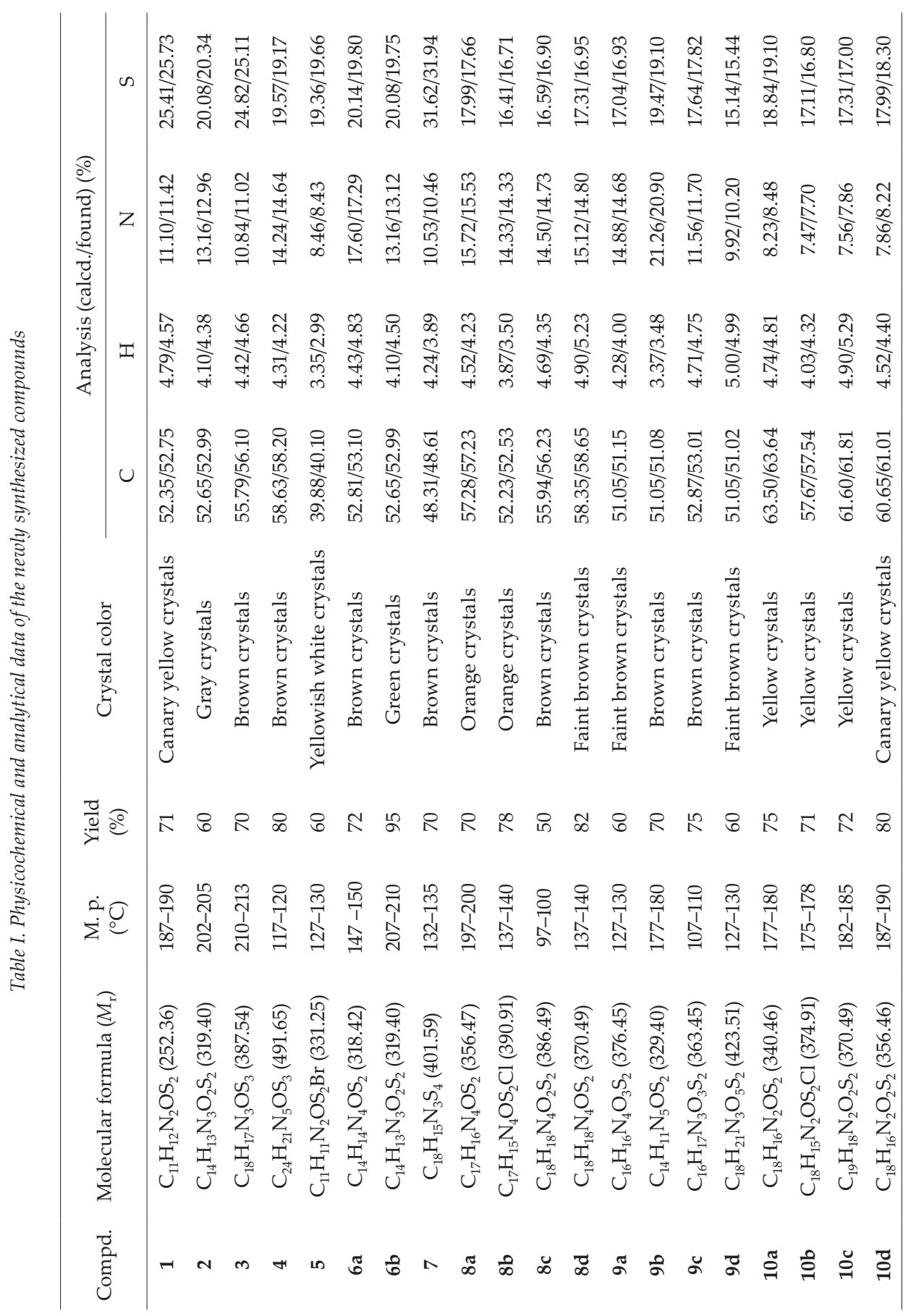




\begin{tabular}{|c|c|c|c|c|c|}
\hline $\begin{array}{l}\stackrel{\circ}{\circ} \\
\equiv\end{array}$ & 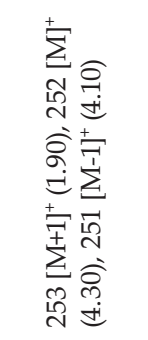 & 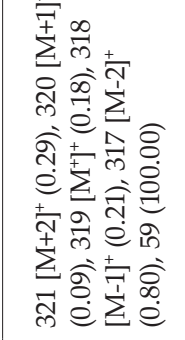 & 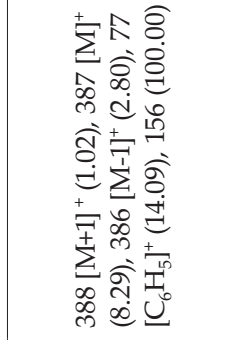 & 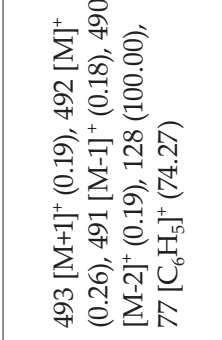 & 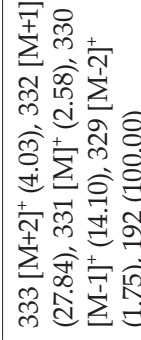 \\
\hline ' & 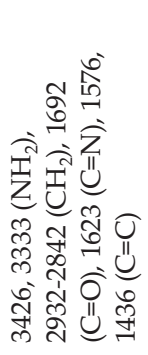 & 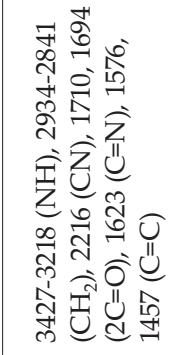 & 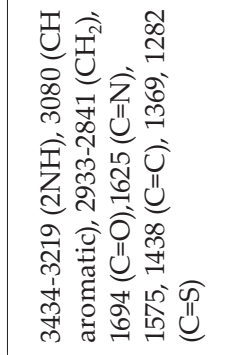 & 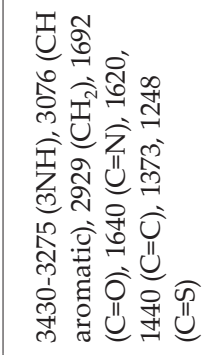 & 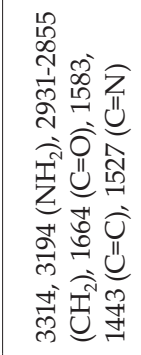 \\
\hline 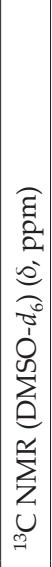 & 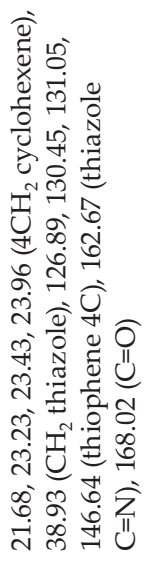 & 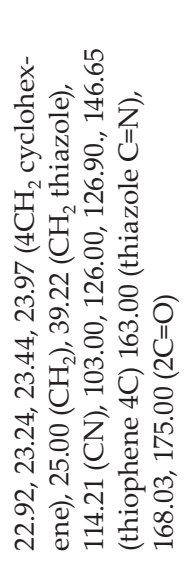 & 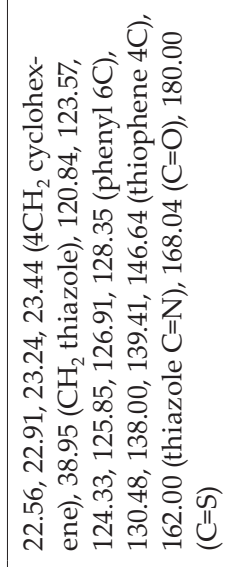 & 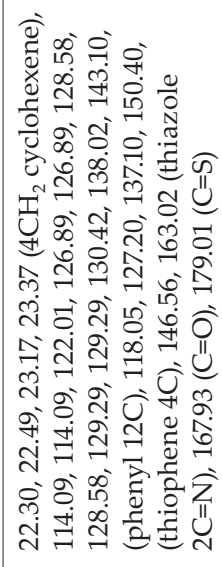 & 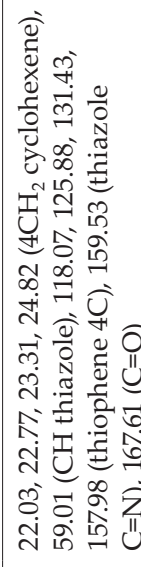 \\
\hline 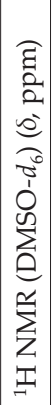 & 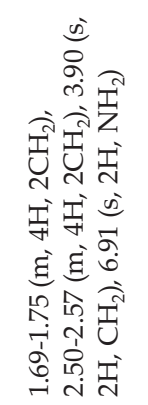 & 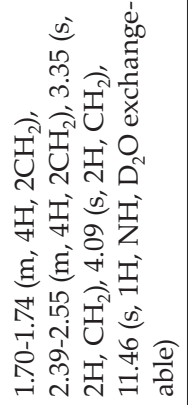 & 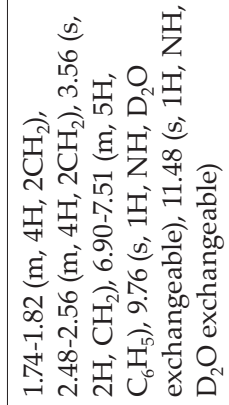 & 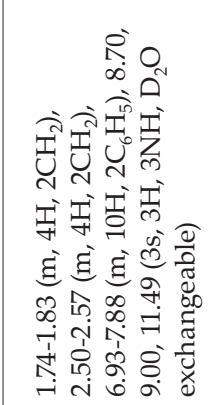 & 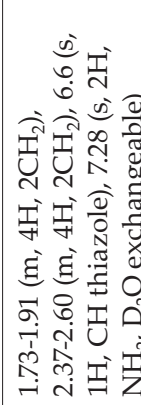 \\
\hline & $r$ & $N$ & $m$ & & \\
\hline
\end{tabular}




\begin{tabular}{|c|c|c|c|c|c|}
\hline 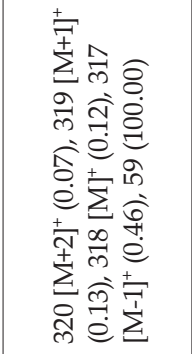 & 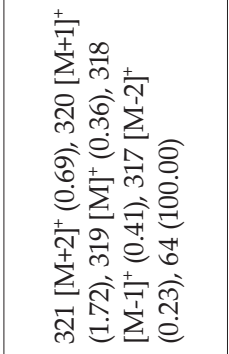 & 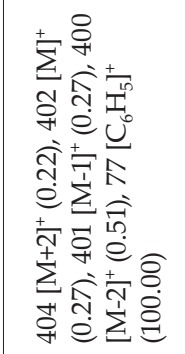 & 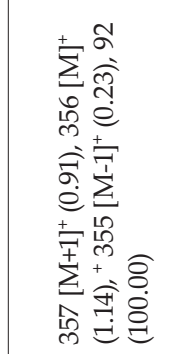 & 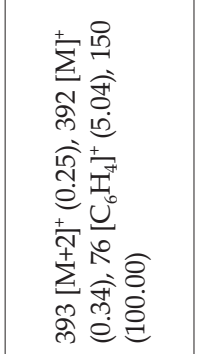 & 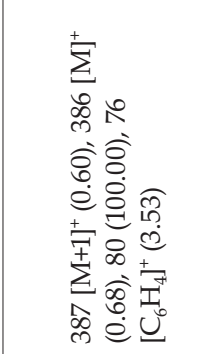 \\
\hline  & 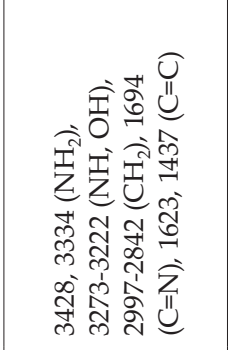 & 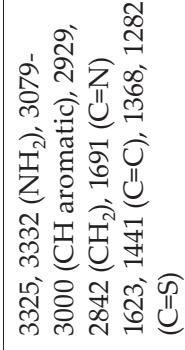 &  & 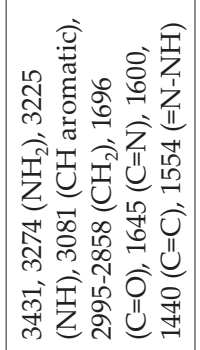 & 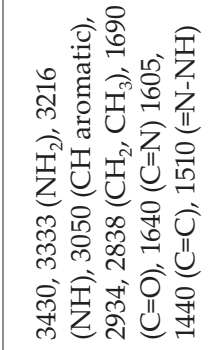 \\
\hline 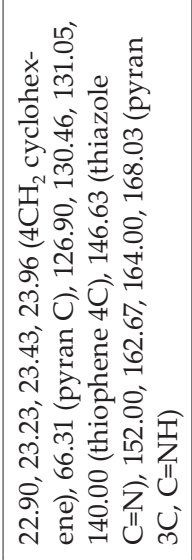 & 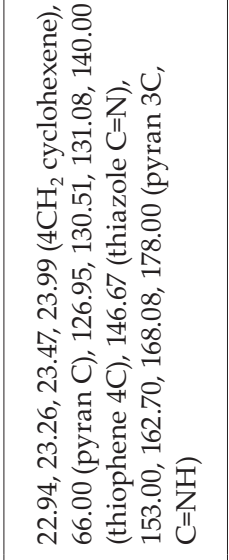 & 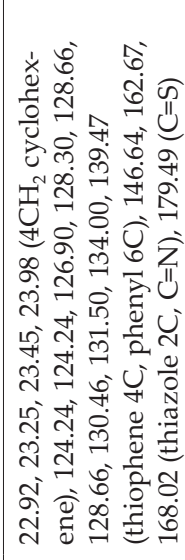 & 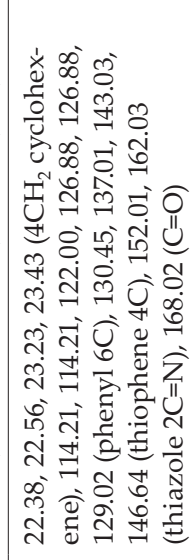 & 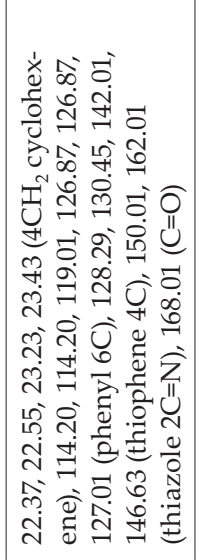 & 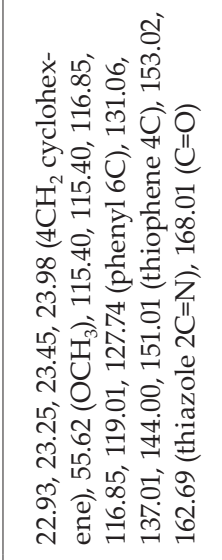 \\
\hline 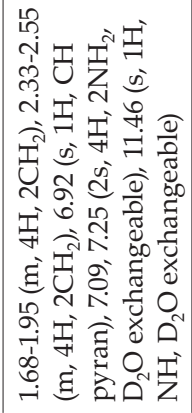 & 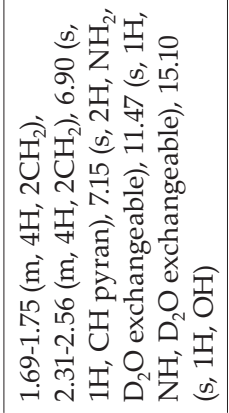 & 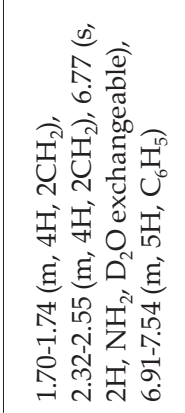 & 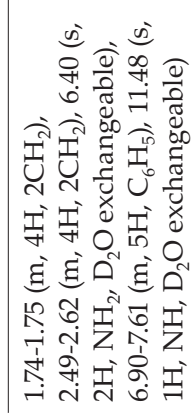 & 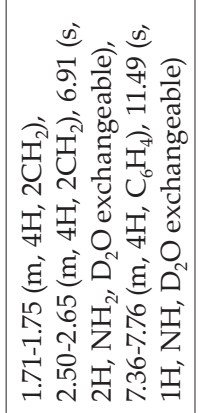 & 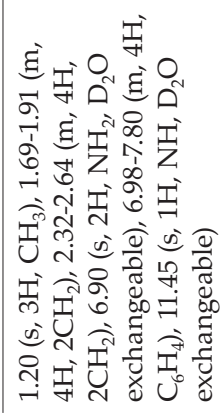 \\
\hline & & & & & \\
\hline
\end{tabular}




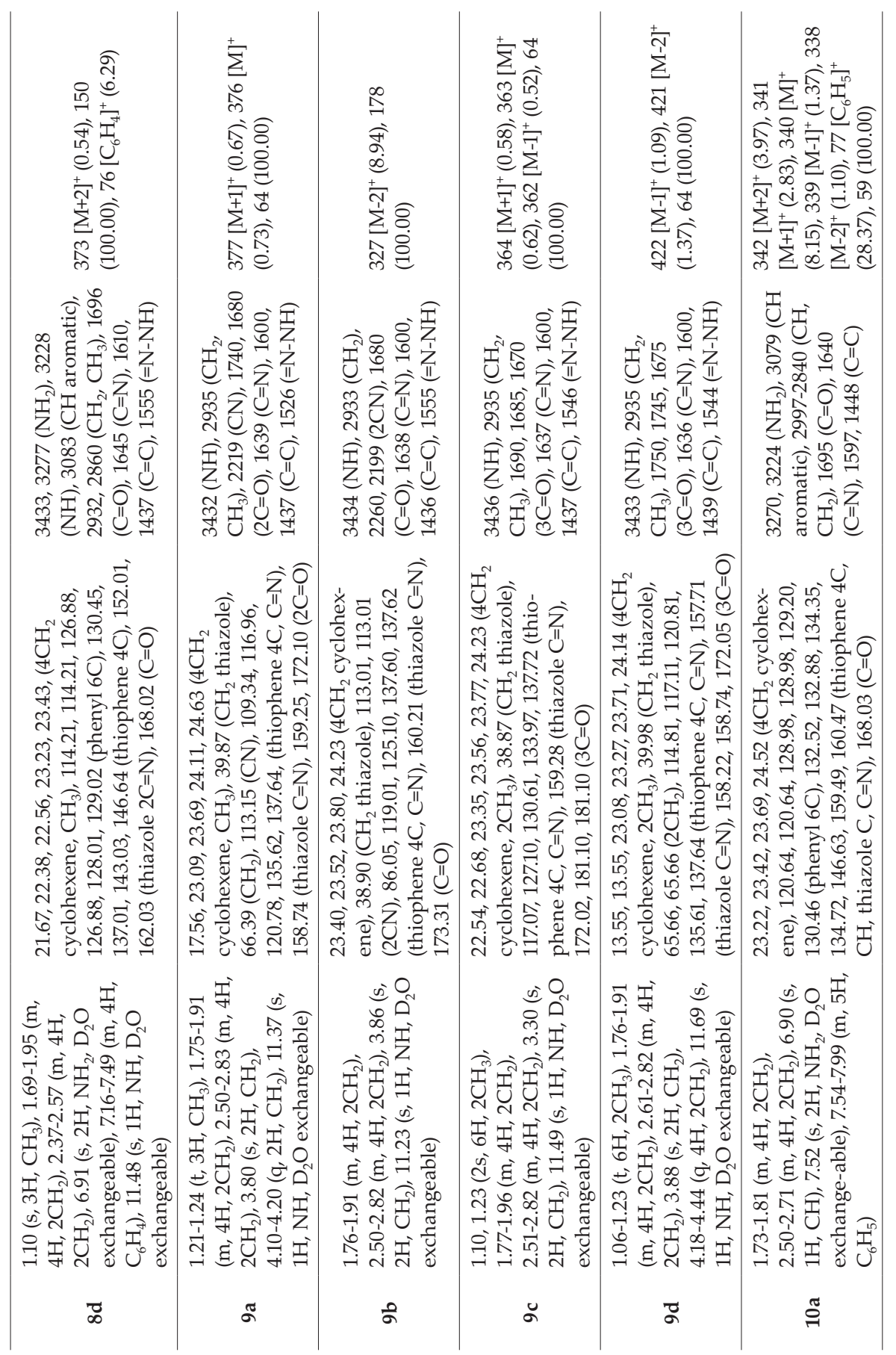




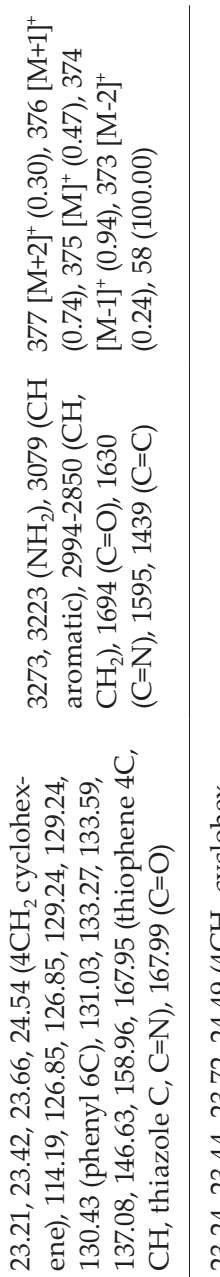

sio 要

ने हैं

0 ㅊ

ते

岂岕预

武装余

हो छ्

क드요

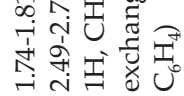

음
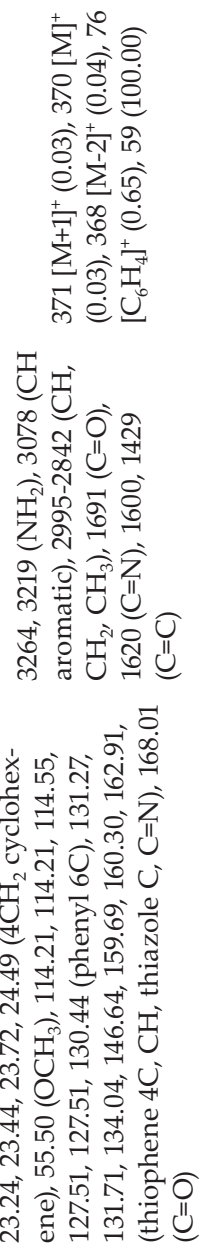

$\stackrel{+}{{ }^{7}}$ 我응 ถิิㅇㅇㅡ

สิ

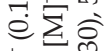

무류

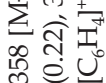

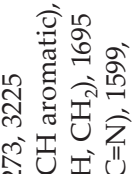

命岂芯

रิ 응

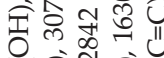

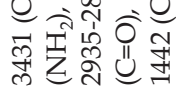

齐另皆

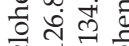

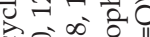

त.

I더

स्रू० के

हี

मुं

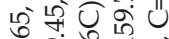

ข่

겅

अ स⿺ 一ी

तें 응음

ते 와 खें

ते ॄิ

\section{ஸे}

車点

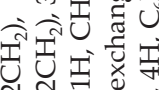

तथ

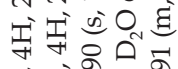

द्वे हों त्रें

응 के

कं ชิ

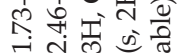

气
ज) 0

०ू คे है

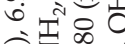

空完完式

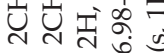

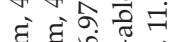

a

तิ

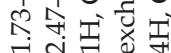

홍

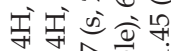

the cyclohexene ring, a singlet at $\delta$ $3.90 \mathrm{ppm}$ for $\mathrm{CH}_{2}$ and a singlet at $\delta$ $6.91 \mathrm{ppm}$ for $\mathrm{NH}_{2}$. In addition, the ${ }^{13} \mathrm{C}$ NMR spectrum revealed four signals at $\delta 21.68,23.23,23.43,23.96$ ppm for four $\mathrm{CH}_{2}$ groups in cyclohexene, a signal at $\delta 38.93$ ppm for the $\mathrm{CH}_{2}$ thiazole moiety. Another four signals at $\delta 126.89,130.45$, $131.05,146.64 \mathrm{ppm}$ were for the thiophene ring, a signal at $\delta 162.67 \mathrm{ppm}$ for thiazole $\mathrm{C}=\mathrm{N}$ and a signal at $\delta$ 168.02 ppm for the $\mathrm{C}=\mathrm{O}$ group. Also, compound 1 reacted with ethyl cyanoacetate in dimethylformamide to give the $\mathrm{N}$-cyanoacetamido derivative. In addition, compound 1 reacted with phenyl isothiocyanate to give the $N$-phenylthiourea derivative $3 .{ }^{1} \mathrm{H}$ NMR spectrum of compound 3 showed two multiplets, at $\delta$ $1.74-1.82$ and $2.48-2.56 \mathrm{ppm}$, for the four $\mathrm{CH}_{2}$ groups of the cyclohexene moiety, a singlet at $\delta 3.56 \mathrm{ppm}$ for the thiazole $\mathrm{CH}_{2}$ group, a multiplet at $\delta 6.90-7.51 \mathrm{ppm}$ for the phenyl ring and two singlets at $\delta 9.76$ and 11.48 ppm for two NH groups. Moreover, the mass spectrum revealed $\mathrm{m} / \mathrm{z}$ at $388[\mathrm{M}+1]^{+}, \mathrm{m} / \mathrm{z}$ at 387 $[\mathrm{M}]^{+}$and $\mathrm{m} / z$ at $77\left[\mathrm{C}_{6} \mathrm{H}_{5}\right]^{+}$for the phenyl moiety. Compound 3 reacted with benzenediazonium chloride in a basic ethanolic solution at $0-5{ }^{\circ} \mathrm{C}$ to give the phenylhydrazo derivative 4 .

Compound 1 reacted with bromine in an acetic acid solution to afford the 5-bromothiazole derivative 5. In addition, compound 1 reacted with either ethyl cyanoacetate or malononitrile in 1,4-dioxane and in the presence of a catalytic amount of triethylamine to give the pyrano[2,3$d$ ] thiazole-2-yl)benzo[ $b$ ] thiophene derivatives $\mathbf{6 a}$ and $\mathbf{6 b}$, respectively. Analytical and spectral data of com- 




Scheme 1

pounds $\mathbf{6 a}, \mathbf{b}$ were consistent with their respective structures. Thus, the ${ }^{1} \mathrm{H}$ NMR spectrum of $\mathbf{6 a}$ (as an example) showed two multiplets at $\delta 1.68-1.95$ and 2.33-2.55 ppm for four $\mathrm{CH}_{2}$ groups of the cyclohexene ring, a singlet at $\delta 6.92 \mathrm{ppm}$ for pyran $\mathrm{CH}$, two singlets at $\delta 7.09$ and $7.25 \mathrm{ppm}\left(\mathrm{D}_{2} \mathrm{O}\right.$ exchangeable) for two $\mathrm{NH}_{2}$ groups and a singlet at $\delta 11.46 \mathrm{ppm}$ for the NH group. The ${ }^{13} \mathrm{C}$ NMR spectrum showed four signals at $\delta 22.90,23.23,23.43,23.96$ ppm for four $\mathrm{CH}_{2}$ groups in the cyclohexene ring, a signal at $\delta 66.31 \mathrm{ppm}$ for the pyran carbon moiety, four signals at $\delta 126.90,130.46,131.05,140.00 \mathrm{ppm}$ for the thiophene carbon ring, a signal at $\delta 146.63 \mathrm{ppm}$ for the thiazole $\mathrm{C}=\mathrm{N}$ and four signals at $\delta 152.00,162.67$, $164.00,168.03 \mathrm{ppm}$ for the pyran ring.

Further, compound 1 underwent the Hantzch reaction (1) through its reaction with elemental sulfur and phenylisothiocyanate to give the 3-phenylthiazolo[4,5- $d]$ thiazole derivative 7 . The structure of the latter product was based on its analytical and spectral data (see experimental section and Tables I and II).

Compound 1 showed high reactivity towards diazonium salts; thus, it reacted with any of the diazonium salts, namely, benzenediazonium chloride, 4-chlorobenzenediazonium chloride, 4-methoxybenzenediazonium chloride or 4-methylbenzenediazonium 

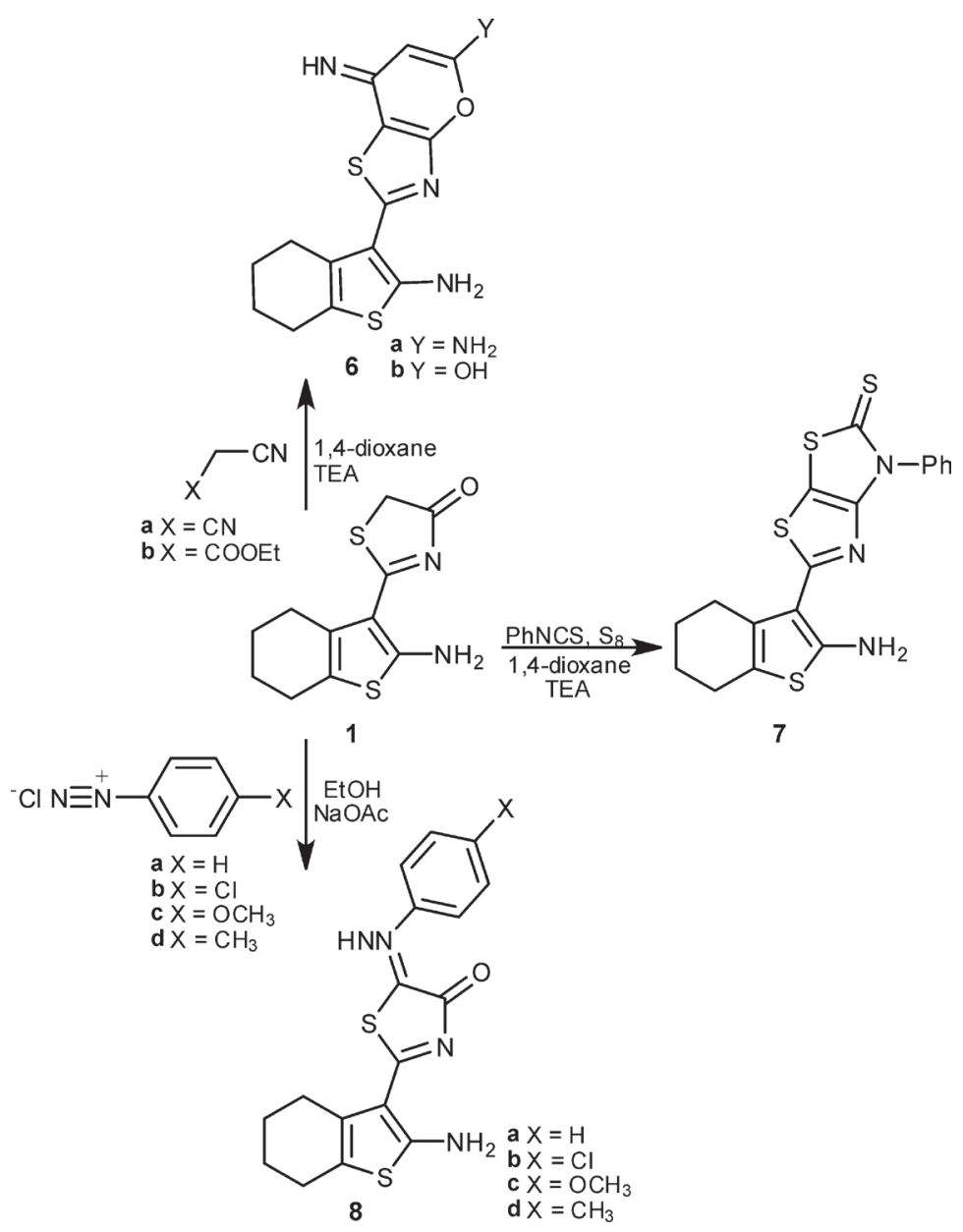

7

Scheme 2

chloride, at $0-5{ }^{\circ} \mathrm{C}$ to give the arylhydrazo derivatives 8a-d, respectively. On the other hand, the 2-amino group present in the tetrahydrobenzo[b]thiophene underwent diazotization and coupling with active methylene reagents. A solution of compound $\mathbf{1}$ in acetic/ hydrochloric acid, when treated with sodium nitrite, gave the intermediate diazonium salt. The latter was coupled with any of ethyl cyanoacetate, malononitrie, acetylacetone or ethyl acetoacetate to give the hydrazone derivatives 9a-d, respectively. Finally, the reaction of compound 1 with any of benzaldehyde, 4-chlorobenzaldehyde, 4-methoxybenzaldehyde or salicylaldehyde afforded the corresponding arylidene derivatives 10a-d, respectively.

Synthetic pathways are presented in Schemes 1-3 and physicochemical and spectral data of the synthesized compounds are given in Tables I and II. Cytotoxicity of the newly synthesized products is displayed in Table III. 


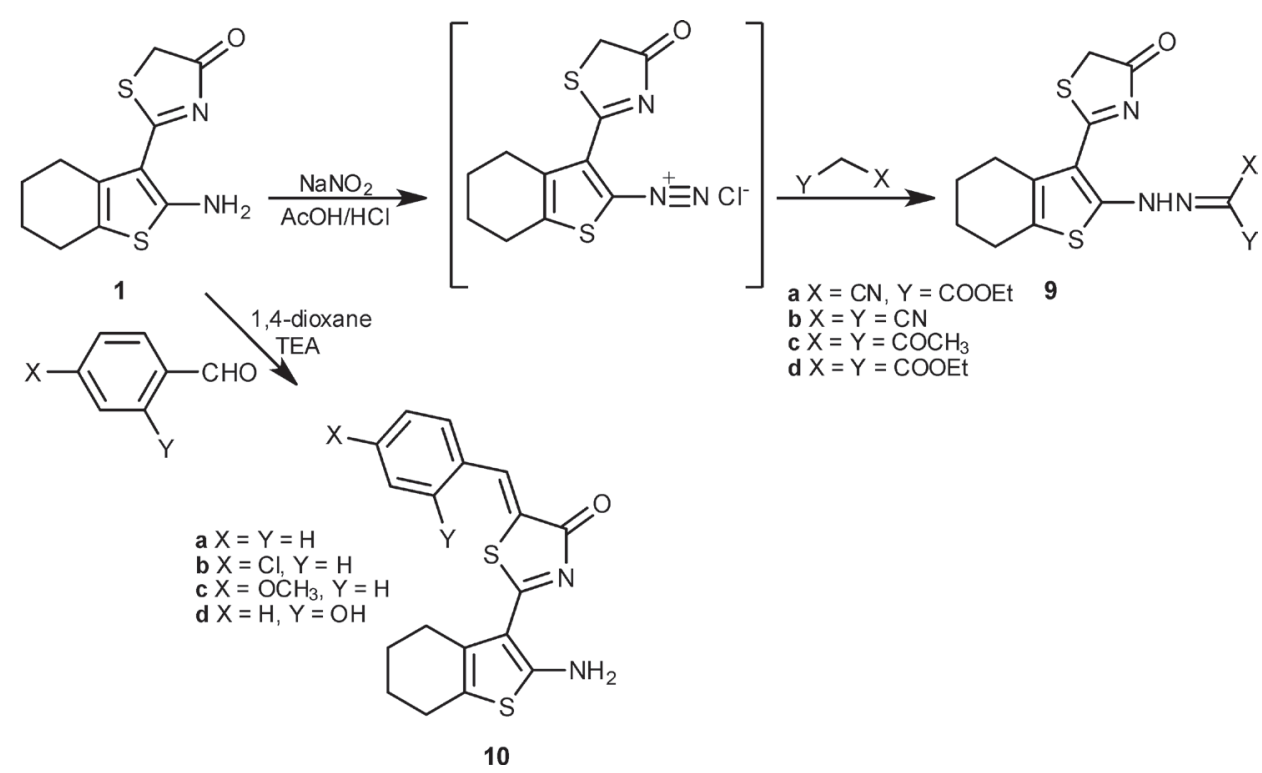

Scheme 3

\section{Evaluation of in vitro cytotoxic activity}

The prepared heterocyclic compounds were tested against six human cancer cell lines, human gastric cancer (NUGC), human colon cancer (DLD-1), human liver cancer (HA22T and HEPG-2), human breast cancer (MCF-7) and nasopharyngeal carcinoma (HONE-1), as well as against normal fibroblast cells (WI-38).

The effects of the newly prepared compounds on six cancer cell lines are presented in Table III. Some heterocyclic compounds exerted marked cytotoxicity against most of the cancer cell lines tested $\left(\mathrm{IC}_{50} 20-100 \mathrm{nmol} \mathrm{L}^{-1}\right)$. Normal fibroblasts cells (WI-38) were affected to a much lesser extent $\left(I C_{50}>100 \mathrm{nmol} \mathrm{L}^{-1}\right)$. It was found that some compounds showed cytotoxicity even higher than the reference CHS-828. Thus, compounds 5, 7, 8a, $9 \mathrm{~b}$ and $\mathbf{1 0 b}$ showed high cytotoxicity towards NUGC, 8 a being of comparable activity to the reference drug. Compounds 3, 4, 5, 6b, 8a, 8b, 8d, 9a and 9d showed high cytotoxicity against DLD-1, with the most active $7,9 \mathbf{b}$ and $\mathbf{1 0 b}$ with $I C_{50}$ markedly lower than that of CHS-828. The same applies to compounds $6 \mathbf{6 a}, \mathbf{9 b}$ and $9 \mathrm{c}$ against HA22T. Moreover, compounds 3, 4, 7, 8a, 8b, 8d, $9 b, 9 d, 10 a$ and $10 b$ showed higher cytotoxicity against HEPG-2 than the reference drug. In the case of HONE-1, $\mathbf{8 b}$ could be considered to be of comparable activity to CHS-828, while compounds $10 \mathbf{c}$ and $\mathbf{8 b}$ showed cytotoxicity comparable to CHS-828 against MCF-7.

Compound $8 \mathrm{a}$ was the most active towards the NUGC cancer cell line, compound $10 \mathrm{~b}$ for DLD-1, compound $\mathbf{6} \mathbf{a}$ for HA22T, compound $\mathbf{8 b}$ for HEPG-2 and HONE-1 and finally compound 10c for MCF-7, all compared to the standard reference CHS-828. It is important to mention that most of the newly synthesized products showed either no or low cytotoxicity towards the normal cell line WI-38. 
R. M. Mohareb et al.: Synthesis and cytotoxicity evaluation of thiazole derivatives obtained from 2-amino-4,5,6,7-tetrahydrobenzo[b] thiophene-3-carbonitrile, Acta Pharm. 67 (2017) 495-510.

Table III. Cytotoxicity of the newly synthesized products against six cancer cell lines and a normal fibroblast cell

\begin{tabular}{|c|c|c|c|c|c|c|c|}
\hline \multirow{2}{*}{ Compd. } & \multicolumn{7}{|c|}{$I C_{50}\left(\mathrm{nmol} \mathrm{L}^{-1}\right)^{\mathrm{a}, \mathrm{b}}$} \\
\hline & NUGC & DLD-1 & HA22T & HEPG-2 & HONE-1 & MCF-7 & WI-38 \\
\hline 1 & $2101 \pm 86$ & $2432 \pm 59$ & $2358 \pm 80$ & $1350 \pm 63$ & $2180 \pm 58$ & $1140 \pm 58$ & NA \\
\hline 2 & $3138 \pm 13$ & $2366 \pm 14$ & $2228 \pm 12$ & $2130 \pm 69$ & $1584 \pm 79$ & $326 \pm 94$ & $650 \pm 77$ \\
\hline 3 & $549 \pm 80$ & $220 \pm 68$ & $318 \pm 35$ & $150 \pm 42$ & $248 \pm 59$ & $291 \pm 48$ & $120 \pm 22$ \\
\hline 4 & $201 \pm 12$ & $127 \pm 17$ & $118 \pm 22$ & $219 \pm 18$ & $1170 \pm 22$ & $1029 \pm 34$ & NA \\
\hline 5 & $38 \pm 18$ & $163 \pm 38$ & $120 \pm 68$ & $3744 \pm 13$ & $441 \pm 38$ & $1264 \pm 64$ & $860 \pm 59$ \\
\hline $6 a$ & $122 \pm 32$ & $3210 \pm 96$ & $59 \pm 22$ & $1245 \pm 39$ & $1140 \pm 60$ & $1130 \pm 84$ & NA \\
\hline $6 b$ & $228 \pm 49$ & $569 \pm 42$ & $213 \pm 70$ & $1112 \pm 59$ & $2052 \pm 60$ & $2011 \pm 84$ & $632 \pm 55$ \\
\hline 7 & $48 \pm 16$ & $55 \pm 12$ & $128 \pm 80$ & $128 \pm 42$ & $248 \pm 59$ & $128 \pm 77$ & $838 \pm 48$ \\
\hline $8 a$ & $23 \pm 80$ & $220 \pm 44$ & $183 \pm 68$ & $224 \pm 29$ & $487 \pm 38$ & $390 \pm 90$ & NA \\
\hline $8 b$ & $350 \pm 57$ & $116 \pm 38$ & $290 \pm 73$ & $120 \pm 38$ & $26 \pm 12$ & $48 \pm 14$ & NA \\
\hline $8 c$ & $2116 \pm 21$ & $2765 \pm 21$ & $2838 \pm 17$ & $3220 \pm 32$ & $2440 \pm 24$ & $2239 \pm 16$ & NA \\
\hline $8 d$ & $320 \pm 59$ & $749 \pm 36$ & $194 \pm 57$ & $499 \pm 29$ & $2871 \pm 17$ & $840 \pm 68$ & NA \\
\hline $9 a$ & $537 \pm 75$ & $440 \pm 38$ & $1165 \pm 70$ & $2766 \pm 12$ & $6273 \pm 32$ & $2533 \pm 21$ & $419 \pm 78$ \\
\hline $9 b$ & $55 \pm 25$ & $48 \pm 12$ & $87 \pm 22$ & $350 \pm 32$ & $449 \pm 43$ & $290 \pm 43$ & NA \\
\hline $9 c$ & $1135 \pm 76$ & $2183 \pm 21$ & $89 \pm 39$ & $1220 \pm 49$ & $2180 \pm 80$ & $2120 \pm 69$ & NA \\
\hline $9 d$ & $302 \pm 67$ & $143 \pm 94$ & $173 \pm 48$ & $392 \pm 66$ & $80 \pm 55$ & $284 \pm 44$ & NA \\
\hline $10 a$ & $1105 \pm 54$ & $2460 \pm 17$ & $2160 \pm 21$ & $214 \pm 84$ & $380 \pm 90$ & $1086 \pm 29$ & NA \\
\hline $10 \mathrm{~b}$ & $80 \pm 22$ & $24 \pm 18$ & $160 \pm 53$ & $284 \pm 79$ & $130 \pm 68$ & $73 \pm 42$ & 872 \\
\hline $10 c$ & $2265 \pm 60$ & $2139 \pm 54$ & $2257 \pm 73$ & $2177 \pm 69$ & $2250 \pm 12$ & $18 \pm 80$ & $262 \pm 52$ \\
\hline $10 d$ & $1232 \pm 69$ & $1166 \pm 79$ & $2225 \pm 94$ & $2216 \pm 13$ & $326 \pm 79$ & $1286 \pm 87$ & NA \\
\hline CHS-828 & $25 \pm 10$ & $2315 \pm 13$ & $2067 \pm 13$ & $1245 \pm 69$ & $15 \pm 60$ & $18 \pm 70$ & NA \\
\hline
\end{tabular}

DLD-1 - colon cancer, HA22T - liver cancer, HEPG-2 - liver cancer, HONE-1 - nasopharyngeal carcinoma, MCF-7 breast cancer, NA - not active, NUGC - gastric cancer, WI-38 - normal fibroblast cells

${ }^{a}$ Drug concentration required to inhibit tumor cell proliferation by $50 \%$ after continuous exposure for 48 h; CHS- 828 was used as positive control; DMSO $0.5 \%$ negative control.

${ }^{\mathrm{b}}$ Mean \pm SEM, $n=3$.

\section{Structure activity relationship}

It is clear from the results in Table III that the thiazole moiety was crucial for the cytotoxic effect of cyclic compounds 1-10a-d. Compounds 3, 4, 5, 6a, 7, 8a, 8b, 8d, 9b-d, 10b and 10c exhibited a marked cytotoxic effect against the different cancer cell lines with 
$I C_{50}$ 's in the nanomolar range. Compound 3 showed high cytotoxicity against the six cell lines and showed some activity against the normal cell line WI-38. Reactivity of compound 3 was attributed to the presence of thiazole together with the $N$-phenylthiourea moiety. On the other hand, compound 5 showed high cytotoxicity against NUGC, HA22T and DLD-1 cell lines with $I C_{50} 38,120$ and $163 \mathrm{nmol} \mathrm{L}^{-1}$. The presence of two cyano groups in compound $9 \mathrm{~b}$ was probably responsible for its higher activity compared to compounds $9 \mathrm{a}, 9 \mathrm{c}$ and $9 \mathrm{~d}$. It is obvious that compound $10 \mathrm{~b}$ showed higher cytotoxicity than $10 \mathrm{a}, 10 \mathrm{c}$ and $10 \mathrm{~d}$ due to the presence of the $\mathrm{Cl}$ group. In conclusion, based on the presented data, the presence of an electron withdrawing group enhanced the potency of the compound.

\section{CONCLUSIONS}

Briefly, we have reported the synthetic strategies for the synthesis of new thiazole derivatives starting from 2-(2-amino-4,5,6,7-tetrahydrobenzo[b]thiophen-3-yl)thiazol$4(5 H)$-one (1). The newly prepared compounds were studied for their anticancer activities on six human cancer cell lines and a normal human cell line. The data showed that the pyrano[2,3-d] thiazole derivative (6a), thiazolo[4,5-d]thiazole derivative (7), 2-(2-amino4,5,6,7-tetrahydrobenzo[b]thiophen-3-yl)thiazole derivatives $(\mathbf{8 a}, \mathbf{b}, \mathbf{1 0 b}, \mathbf{c})$ and the 4,5,6,7-tetrahydrobenzo[b]thiophen-2-yl)carbonohydrazonoyl derivative (9b) were most active against all the tested cancer cell lines. Taking into account their non-toxicity towards the normal cell line, compounds $\mathbf{6 a}, \mathbf{8 a}, \mathbf{8 b}$ and $\mathbf{9 b}$ might be considered to be of potential therapeutic assistance.

\section{REFERENCES}

1. I. Lagoja, C. Pannecouque, G. Griffioen, S. Wera, V. M. Rojasdelaparra and A. V. Aerschot, Substituted 2-aminothiazoles are exceptional inhibitors of neuronal degeneration in tau-driven models of Alzheimer's disease, Eur. J. Med. Chem. 43 (2011) 386-392; https://doi.org/org/10.1016/j.ejps.2011.05.014

2. S. Kamila, K. Mendoza and E. R. Biehl, Microwave-assisted Hantzsch thiazole synthesis of Nphenyl-4-(6-phenylimidazo[2,1-b]thiazol-5-yl)thiazol-2-amines from the reaction of 2-chloro-1-(6phenylimidazo[2,1-b]thiazol-5-yl)ethanones and thioureas, Tetrahedron Lett. 53 (2012) 4921-4924; https://doi.org/10.1016/j.tetlet.2012.06.116

3. A. H. Cook, I. Heilbron, S. F. Macdonald and A. P. Mahadevan, 226. Studies in the azole series. Part XII. Some thiazolopyrimidines, J. Chem. Soc. 1949, 1064-1068; https://doi.org/10.1039/ JR9490001064

4. R. Robinson, CCXXXII. - A new synthesis of oxazole derivatives, J. Chem. Soc. 95 (1909) 2167-2174; https://doi.org/org/10.1039/CT9099502167

5. S. Gabriel, Eine Synthese von Oxazolen und Thiazolen. I, Ber. Dtsch. Chem. Ges. 43 (1910) 134-138; https://doi.org/10.1002/cber.19100430117

6. S. Gabriel, Synthese von Oxazolen und Thiazolen II, Ber. Dtsch. Chem. Ges. 43 (1910) 1283-1287; https://doi.org/10.1002/cber.19100430219

7. T. M. Potewar, S. A. Ingale and K. V. Srinivasan, Efficient synthesis of 2,4-disubstituted thiazoles using ionic liquid under ambient conditions: a practical approach towards the synthesis of fanetizole, Tetrahedron 63 (2007) 11066-11069; https://doi.org/10.1016/j.tet.2007.08.036 
8. M. V. B. Reddy, D. Srinivasulu, K. Peddanna, Ch. Apparao and P. Ramesh, Synthesis and antioxidant activity of new thiazole analogues possessing urea, thiourea, and selenourea functionality, Synth. Commun. 45 (2015) 2592-2600; https://doi.org/org/10.1080/00397911.2015.1095929

9. M. Shiradkar, G. V. S. Kumar, V. Dasari, S. Tatikonda, K. C. Akula and R. Shah, Clubbed triazoles: a novel approach to antitubercular drugs, Eur. J. Med. Chem. 42 (2007) 807-816; https://doi. org/10.1016/j.ejmech.2006.12.001

10. M. R. Shiradkar, K. K. Murahari, H. R. Gangadasu, T. Suresh, C. A. Kalyan, D. Panchal, R. Kaur, P. Burange, J. Ghogare, V. Mokale and M. Raut, Synthesis of new S-derivatives of clubbed triazolyl thiazole as anti-Mycobacterium tuberculosis agents, Bioorg. Med. Chem. 15 (2007) 3997-4008; https://doi.org/10.1016/j.bmc.2007.04.003

11. A. Ayati, S. Emami, A. Asadipour, A. Shafiee and Al. Foroumadi, Recent applications of 1,3-thiazole core structure in the identification of new lead compounds and drug discovery, Eur. J. Med. Chem. 97 (2015) 699-718; http://dx.doi.org/10.1016/j.ejmech.2015.04.015

12. L. Yurttas, Y. Özkay, Z. A. Kaplancikli, Y. Tunali and H. Karaca, Synthesis and antimicrobial activity of some new hydrazone bridged thiazole-pyrrole derivatives, J. Enzyme Inhib. Med. Chem. 28 (2013) 830-835; https://doi.org/10.3109/14756366.2012.688043

13. B. Ghasemi and M. Najimi, Antibacterial effect of thiazole derivatives on Rhodoccocus equi, Brucella abortus, and Pasteurella multocida, Iran. J. Vet. Med. 10 (2016) 47-52.

14. G. M. Reddy, J. R. Garcia, V. H. Reddy, A. M. de Andrade, A. Jr. Camilo, R. A. P. Ribeiro and S. R. de Lazaro, Synthesis, antimicrobial activity and advances in structure-activity relationships (SARs) of novel tri-substituted thiazole derivatives, Eur. J. Med. Chem. 123 (2016) 508-513; https:// doi.org/10.1016/j.ejmech.2016.07.062

15. R. N. Sharma, F. P. Xavier, K. K. Vasu, S. C. Chaturvedi and S. S. Pancholi, Synthesis of 4-benzyl1,3-thiazole derivatives as potential anti-inflammatory agents: an analogue-based drug design approach, J. Enzyme Inhib. Med. Chem. 24 (2009) 890-897; https://doi.org/ 10.1080/14756360802519558

16. J. Balzarini, B. Orzeszko, J. K. Maurin, and A. Orzeszko, Synthesis and anti-HIV studies of 2-adamantyl-substituted thiazolidin-4-ones, Eur. J. Med. Chem. 42 (2007) 993-1003; https://doi. org/10.1016/j.ejmech.2007.01.003

17. W. C. Patt, H. W. Hamilton, M. D. Taylor, M. J. Ryan, D. G. Jr. Taylor, C. J. C. Connolly, A. M. Doherty, S. R. Klutchko, I. Sircar, B. A. Steinbaugh, B. L. Batley, C. A. Painchaud, S. T. Rapundalo, B. M. Michniewicz and S. C. J. Olson, Structure-activity relationships of a series of 2-amino-4thiazole containing renin inhibitors, J. Med. Chem. 35 (1992) 2562-2572; https://doi.org/10.1021/ jm00092a006

18. H. Cousse, G. Mouzin, B. Bonnaud, J. P. Tarayre and J. P. Couzinier, Studies of arylthiazole oxamates in relation to oral antiallergic activity, Arzneimittelforschung 36 (1986) 1391-1393.

19. N. Ergenç, G. Capan, N. S. Günay, S. Ozkirimli, M. Güngör, S. Ozbey and E. Kendi, Synthesis and hypnotic activity of new 4-thiazolidinone and 2-thioxo-4,5-imidazolidinedione derivatives, Arch. Pharm. (Weinheim) 332 (1999) 343-347; https://doi.org/10.1002/(SICI)1521-4184(199910)332

20. F. Bonina, F. Guerrera, M. C. Sarvà, M. A. Siracusa, A. Caruso, M. G. Leone and M. A. Roxas, Synthesis and analgesic antiinflammatory activities of 2-aryl-ethenyl-4-aryl-thiazole-5-acetic acids, Farmaco Sci. 42 (1987) 905-913.

21. H. He, X. Wang, L. Shi, W. Yin, Z. Yang, H. He and Y. Liang, Synthesis, antitumor activity and mechanism of action of novel 1,3-thiazole derivatives containing hydrazide-hydrazone and carboxamide moiety, Bioorg. Med. Chem. Lett. 26 (2016) 3263-3270; https://doi.org/10.1016/j. bmcl.2016.05.059

22. G. Turan-Zitouni, M. D. Altıntop, A. Özdemir, Z. A. Kaplancıklı, G. A. Çiftçi and H. E. Temel, Synthesis and evaluation of bis-thiazole derivatives as new anticancer agents, Eur. J. Med. Chem. 107 (2016) 288-294; https://doi.org/10.1016/j.ejmech.2015.11.002 
23. I. Nabih, F. El-Hawary and H. Zoorob, Structure and activity of thiazole-type schistosomicidal agents, J. Pharm. Sci. 61 (1972) 1327-1328; https://doi.org/10.1002/jps.2600610838

24. R. R. Gupta, M. Kumar and V. Gupta, Heterocyclic Chemistry - Volume II: Five-Membered Heterocycles, 1st ed., Springer-Verlag, Berlin-Heidelberg 1999, pp. XI-638.

25. E. M. Samir, A. S. Abouzied and F. I. Hamed, The synthesis and cytotoxicity of novel thiophene derivatives derived from 2-(4-oxo-4,4-dihydrothiazol-2-yl) acetonitrile, Int. J. Org. Chem. 6 (2016) Article ID 66590 (10 pages); https://doi.org/10.4236/ijoc.2016.62009

26. V. Combes, G. J. Guillemin, T. Chan-Ling, N. H. Hunt and G. E. R. Grau, The crossroads of neuroinflammation in infectious diseases: endothelial cells and astrocytes, Trends Parasitol. 28 (2012) 311-319; https://doi.org/10.1016/j.pt.2012.05.008

27. L. Roemer, S. M. Orsillo and K. Salters-Pedneault, Efficacy of an acceptance-based behavior therapy for generalized anxiety disorder: evaluation in a randomized controlled trial, J. Consult. Clin. Psychol. 76 (2008) 1083-1089; https://doi.org/10.1037/a0012720

28. J. Li, B. Mookerjee and J. Wagner, Purification of melanoma reactive T cell by using a monocytebased solid phase T-cell selection system for adoptive therapy, J. Immunother. 31 (2008) 81-88; https://doi.org/10.1097/CJI.0b013e318157c668 